\title{
Implementasi Metode QINQ Pada Jaringan Metro Ethernet Untuk Memaksimalkan Penggunaan VLAN Menggunakan Teknologi GPON Studi Kasus : PT. Telkom Indonesia
}

\author{
Prayoga Pangestu ${ }^{1}$, Raka Yusuf ${ }^{2}$ \\ Program Studi Informatika Universitas Mercu Buana Jakarta \\ E-mail: 141516120011@,student.mercubuana.ac.id ${ }^{1}$, raka@mercubuana.ac.id ${ }^{2}$
}

Pangestu, P. P. P., \& Yusuf, R. . (2021). Implementasi Metode QINQ Pada Jaringan Metro Ethernet Untuk Memaksimalkan Penggunaan VLAN Menggunakan Teknologi GPON Studi Kasus : PT. Telkom Indonesia. Technomedia Journal, 6(1 Agustus). Diambil dari

https://ijc.ilearning.co/index.php/TMJ/article/view/1551

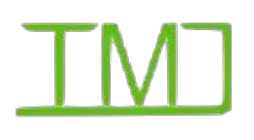

\section{ABSTRAK}

VLAN adalah salah satu komponen dalam sistem jaringan yang berfungsi sebagai pembagi jaringan, penggunaan VLAN sangat membantu dalam melakukan pemetaan jaringan pada perangkat router atau switch. Penggunaan VLAN menjadi hal yang pasti dalam membangun arsitektur jaringan yang efektif dan fleksibel, tidak terkecuali pada salah satu perusahaan Provider penyedia jasa jaringan seperti PT Telkom Indonesia. Penggunaan VLAN sesuai dengan standar yang berlaku dibatasi dengan spesifikasi 802.1Q yaitu terbatas pada 1- 4096 VLAN ID yang dapat digunakan. Hal ini akan menjadikan masalah ketika ditemukan VLAN ID yang sudah digunakan untuk satu jaringan maka tidak dapat digunakan lagi untuk jaringan lain. Masalah tersebut dapat ditemukan juga pada PT. Telkom Indonesia yang menggunakan GPON (Gigabit Passive Optical Network) untuk memenuhi kebutuhan pelanggannya. Berdasarkan permasalahan yang ditemui, peneliti bermaksud menggunakan metode VLAN QinQ pada Teknologi GPON (Gigabit Passive Optical Network), untuk menyelesaikan permasalahan keterbatasan VLAN ID yang mungkin ditemui ketika memenuhi kebutuhan dari pelanggan PT. Telkom Indonesia. Adapun metode yang digunakan dalam penelitian ini adalah dengan membungkus VLAN ID Pelanggan ke dalam VLAN ID Service menggunakan perangkat GPON OLT dan ONT Huawei.

Kata kunci : GPON, Metro,QinQ, VLAN

\section{ABSTRACT}

$V L A N$ is part of network system that serves as the divider, the use of vlan very helpful in mapping the router or switch on the device. The use of vlan become a sure thing in building architecture of effective and flexible. Not except one of a company service providers like PT. Telkom Indonesia. The use of vlan according to the standard of limited to specification 802.19 with the limited to $1-4096$ VLAN ID can be used. This will make a problem when found vlan id who have been used for a network will not get used again to another network. The problem also can be found on PT Telkom Indonesia who uses GPON (Gigabit Passive Optical Network) to meet the needs of their customers. Based on the problems encountered, researchers want to use of vlan qinq on technology GPON (Gigabit Passive Optical Network) To solve the problem limited vlan id that might be encountered when meet the needs of from customers PT. Telkom Indonesia . 
As for the method in use in this research is by wrapping vlan id customers into vlan id service using the device GPON OLT and ONT Huawei.

Keywords: GPON, Metro, QinQ, VLAN

\section{PENDAHULUAN}

Salah satu Produk Telekomunikasi dari PT Telkom Indonesia adalah Metro Ethernet. Dalam Konfigurasinya Metro Ethernet dibedakan menjadi dua topologi utama yaitu P2P ( Point to Point ) dan P2MP (Point to Multipoint) yang diatur dengan VLAN (Virtual Local Area Network) sehingga setiap kebutuhan layanan akan memiliki VLAN ID tersendiri [1]. Untuk memenuhi kebutuhan pelanggannya Telkom Indonesia menggunakan teknologi GPON (Gigabit Passive Optical Network). GPON (Gigabit Passive Optical Network) merupakan teknologi akses yang berbasis kabel fiber optic yang dikembangkan oleh ITU-T via G.984.[1] Dalam penerapan VLAN, permasalahan yang sering dihadapi adalah terbatasnya VLAN ID yang bisa digunakan yaitu hanya memiliki jumlah 4094 dari spesifikasi 802.1Q,[8] selain itu adanya permintaan VLAN ID tertentu dari pelanggan menambah permasalahan yang akan dihadapi dalam memenuhi kebutuhan layanan. Karena pelanggan memiliki alokasi VLAN ID tersendiri yang harus dipenuhi [2]. Untuk mengatasi permasalahan yang terjadi peneliti bermaksud menggunakan konsep inner-vlan double tagging atau bisa juga disebut dengan $\mathrm{Q}$ in Q Tunneling dengan konsep menggunakan satu VLAN ID untuk satu pelanggan sehingga kebutuhan VLAN ID internal dari pelanggan dapat terealisasi dan dapat dikelola masing masing administrator jaringan, hal ini memungkinkan untuk dapat mewujudkan pengelolaan VLAN ID yang lebih efektif [3].

Adapun tujuan dan manfaat dari penelitian yang peneliti lakukan adalah :

1. Mengimplementasikan metode QinQ pada jaringan Metro Ethernet dengan menggunakan teknologi GPON untuk pelanggan PT Telkom Indonesia .

2. Memenuhi kebutuhan VLAN ID pelanggan PT Telkom Indonesia .

3. Mengurangi kesalahan konfigurasi VLAN ID yang mungkin terjadi.

Dan Manfaat yang dapat diperoleh dari penelitian ini adalah :

Pelanggan dapat menentukan VLAN ID yang akan dilewatkan tanpa bantuan administrator dari PT Telkom Indonesia dan tanpa khawatir VLAN ID yang akan di lewatkan sudah di paka. Selain itu akan menciptakan sistem jaringan yang lebih aman.

\section{PERMASALAHAN}




\section{A. Metro Ethernet}

Metro Ethernet adalah layanan High capacity data network solution berbasis Ethernet yang memberikan fleksibilitas, kesederhanaan serta jaminan Quality Of Service (QoS) bagi pelanggan bisnis Internet Service Provider (ISP) maupun Other Licenced Operator (OLO) kapasitas yang dapat dilayani oleh Metro Ethernet adalah hingga kecepatan 10 Gbps dan dengan jarak tempuh puluhan bahkan ratusan kilometer [4].

\section{B. GPON (Gigabit Passive OpticalNetwork)}

GPON merupakan teknologi FTTx dengan menggunakan media fiber optic. Prinsip kerjanya adalah ketika OLT mengirimkan sinyal, maka akan ada pembagi jaringan yaitu splitter yang memungkinkan fiber optic tunggal dapat mengirim ke berbagai ONU [5]. Arsitektur dari GPON adalah menggunakan TDM (Time Division Multiplexing). Adapun komponen dari GPON itu sendiri adalah sebagai berikut :

1. OLT (Optical Line Terminal)

OLT adalah sebagai pusat dari sistem jaringan GPON. OLT memiliki fungsi utama merubah sinyal elektrik menjadi optic.

2. ODN (Optical Distribution Network)

ODN adalah jaringan perantara antara OLT dengan ONT fungsi utamanya adalah sebagai distributor jaringan. ODN dapat ditemukan di Rumah Kabel. ODN memastikan sarana transmisi dari OLT ke pengguna tersedia dan begitupun juga sebaliknya .

3. ONT (Optical Network Termination)

ONT adalah perangkat aktif yang berada di sisi pelanggan yang memiliki fungsi utama mentransmisikan suara, data dan video yang melewati jaringan GPON kepada para pelanggan dan OLT. 


\section{VLAN}

VLAN adalah solusi utama dalam mengatur jaringan pada layer 2 (data link) dengan menggunakan VLAN, pengguna dapat mengatur lalu lintas data antar perangkat switch ataupun router.

\section{QinQ}

QinQ adalah mengenkapsulasi VLAN tag dari sebuah private network dengan VLAN tag dari public network. Sehingga frame membawa dua buah identitas VLAN. Hasilnya VLAN dari private network dapat dilewatkan pada VLAN tag dari public network [6].

\section{METODOLOGI PENELITIAN}

\section{A. Teknik Pengumpulan Data}

1. Observasi : Penulis melakukan pengamatan pada konfigurasi dan kebutuhan yang dibutuhkan oleh pelanggan.

2. Wawancara : Penulis melakukan wawancara dengan salah satu pelanggan PT Telkom Indonesia .

3. Studi Pustaka : Metode yang digunakan untuk menambah wawasan dan mendapatkan sumber pengetahuan untuk membantu penelitian, baik dari Buku, E-journal dan Internet yang berhubungan dengan masalah yang akan diteliti. 


\section{B. Diagram Alir Penelitian}

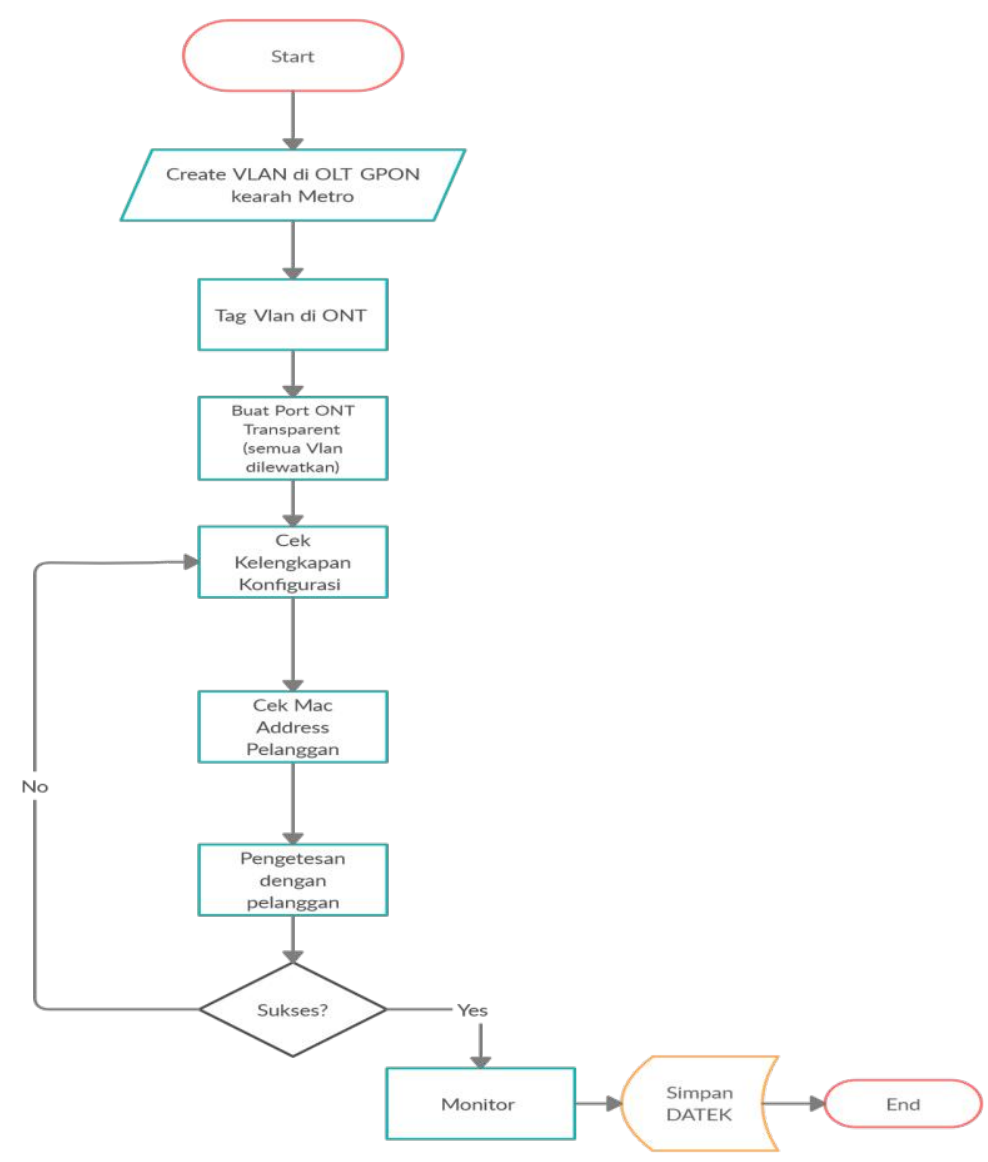

Gambar 3. 1 Diagram Alir Penelitan

1. Create VLAN di OLT GPON kearah Jaringan Metro

Pada tahapan ini Peneliti menambahkan atau membuat VLAN yang sesuai dengan SVLAN (Service VLAN) dari layanan Metro-E pada OLT GPON.

2. Tag VLAN di ONT

Pada tahapan ini Peneliti menambahkan Service VLAN pada ONT dengan menggunakan GEM (GPON Encapsulation Method)

3. Konfigurasi Port Mode Transparent pada ONT

Melakukan konfigurasi port mode transparent pada ONT yang dimaksudkan untuk memperbolehkan semua vlan yang ditambahkan oleh pelanggan di lewatkan..

4. Cek Kelengkapan Konfigurasi

Pada tahapan ini dilakukan pengecekan kelengkapan k konfigurasi pada GPON.

5. Cek Mac Address Pelanggan

6. Setelah melakukan tahapan pengecekan konfigurasi, maka pelanggan diperkenankan untuk melakukan plug in pada port ONT yang telah disediakan, 
kemudian melakukan tag VLAN kearah port ONT. Setelah melakukan hal tersebut dari peneliti melakukan pengecekan apakah Mac-Address dari pelanggan sudah terbaca pada jaringan.

7. Pengetesan dengan Pelanggan

8. Pengetesan pada pelanggan dengan menggunakan bantuan IP Address pada Interface VLAN yang ditambahkan pada CVLAN (Customer VLAN) di perangkat pelanggan dengan ilustrasi sebagai berikut :

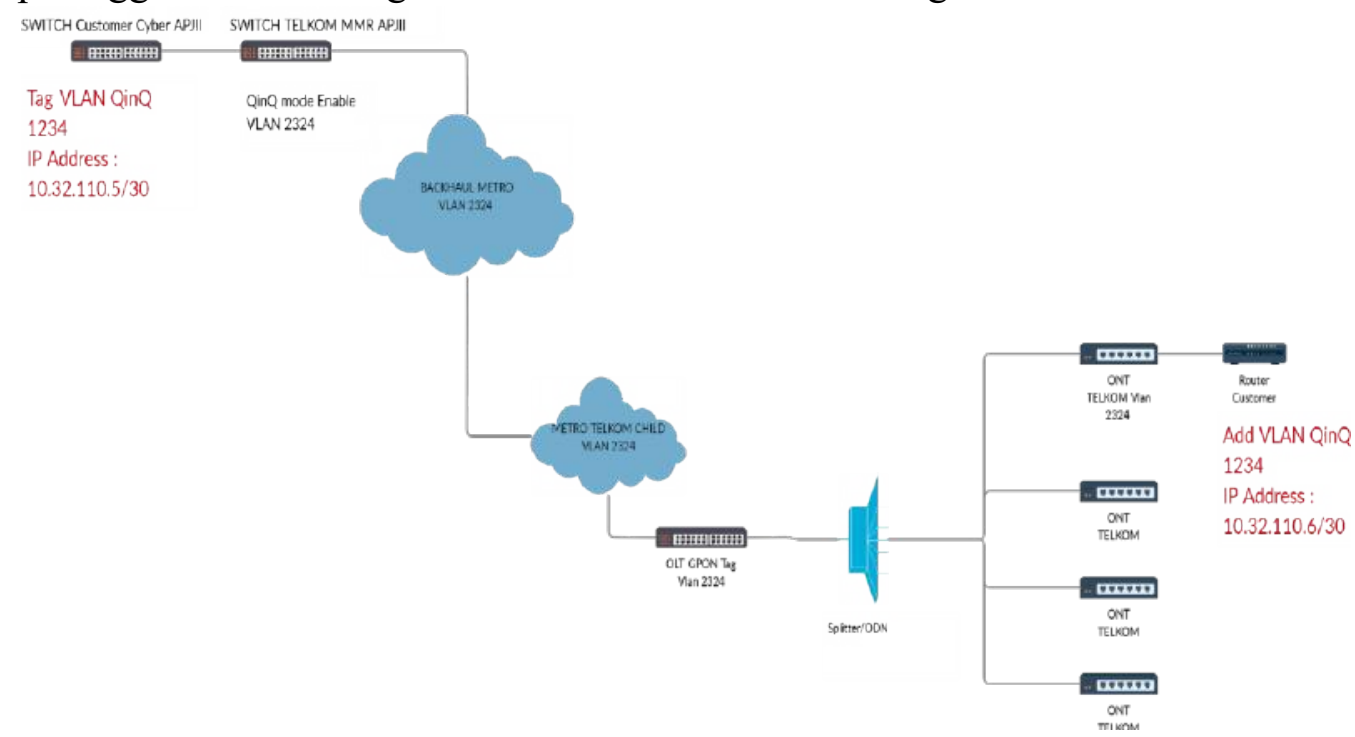

Gambar 3. 2 Topologi Pengetesan

Setelah melakukan penambahan IP Address pada interface VLAN, maka dilakukan pengetesan pengiriman paket data ICMP (Internet Control Message Protocol) menggunakan ping dengan memperhatikan beberapa parameter seperti packet loss dan delay saat melakukan pengiriman paket. Saat melakukan pengiriman paket ICMP maka akan terjadi 2 kondisi yaitu ping test gagal dan ping test berhasil [7]. 
- Gagal : ping test akan dikatakan gagal jika paket yang dikirim tidak reply atau paket loss yang diterima tinggi seperti pada parameter berikut :

Tabel 3. 2 Tabel kategori ping test

\begin{tabular}{|c|c|c|}
\hline Nilai & Persentase (\%) & Indeks \\
\hline 4 & 0 & Sangat Bagus \\
\hline 3 & 3 & Bagus \\
\hline 2 & 15 & Kurang Bagus \\
\hline 1 & 25 & Jelek \\
\hline
\end{tabular}

Maka proses akan di ulang dengan mengecek Kembali konfigurasi yang mungkin kurang lengkap.

- Sukses : ping test dikatakan sukses jika paket yang dikirim reply dan dengan parameter yang baik.

7. Monitor Layanan

Setelah sukses melakukan test ping maka layanan akan dimonitor selama waktu yang ditentukan oleh pelanggan.

\section{Simpan Data Teknis}

Setelah selesai memonitor layanan maka hal yang perlu dilakukan adalah menyimpan Data Teknis yang berhubungan dengan layanan agar Ketika terjadi gangguan akan lebih mudah melakukan penanganan / troubleshooting [8].

\section{HASIL DAN PEMBAHASAN}

\section{A. Topologi Sebelum menggunakan Metode VLAN QinQ}

Jaringan Metro Ethernet pada PT Telkom Indonesia yang dijadikan contoh pada penelitian kali ini adalah jaringan P2MP (Point to Multi Point) yang terdiri dari satu Penghubung utama (Backhaul) dan beberapa End point Site (Child) membentuk jaringan yang terpusat dari beberapa Child ke satu Backhaul dengan VLAN sebagai perantara antara Backhaul dan Child [9]. 


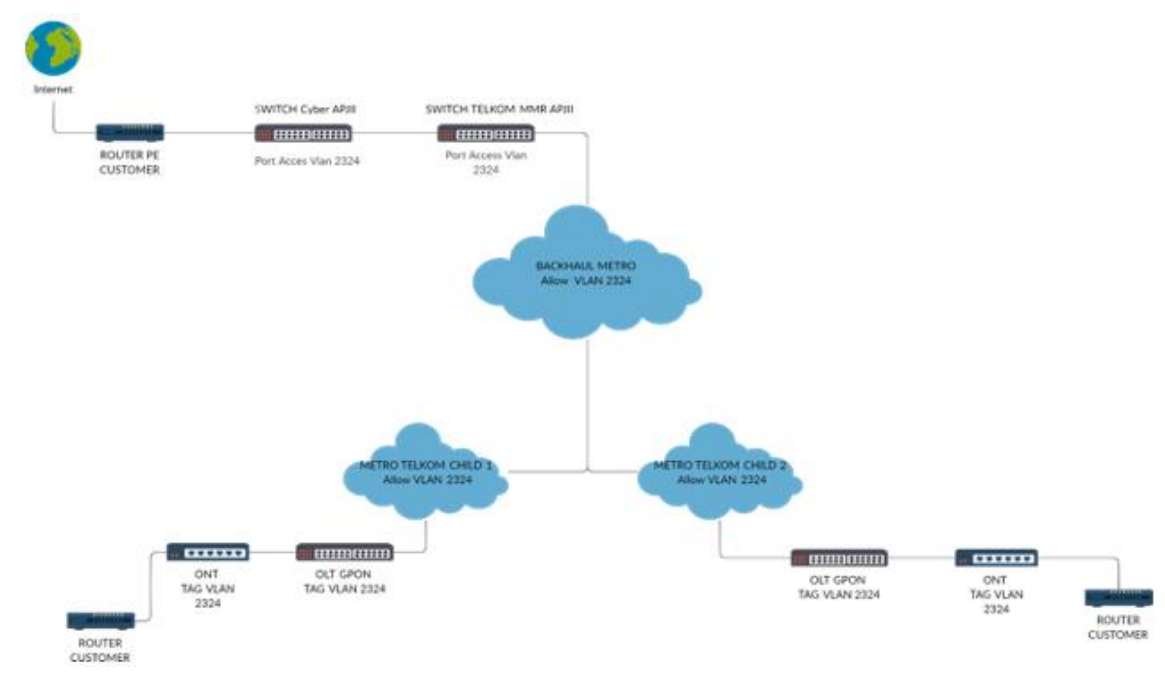

Gambar 4. 1 Topologi tanpa QinQ

Gambar 4.1 menggambarkan topologi layanan tanpa menggunakan metode QinQ VLAN . Dalam topologi tersebut hanya terdapat satu VLAN yang menghubungkan antara Backhaul dan Child dari layanan pelanggan[10]. Dikarenakan kebijakan manajemen vlan pada provider layanan yaitu satu VLAN untuk satu layanan. Hal ini tidak memungkinkan adanya VLAN ID tambahan yang dapat digunakan oleh pelanggan [11].

\section{B. Topologi Setelah Menggunakan metode VLAN QinQ}

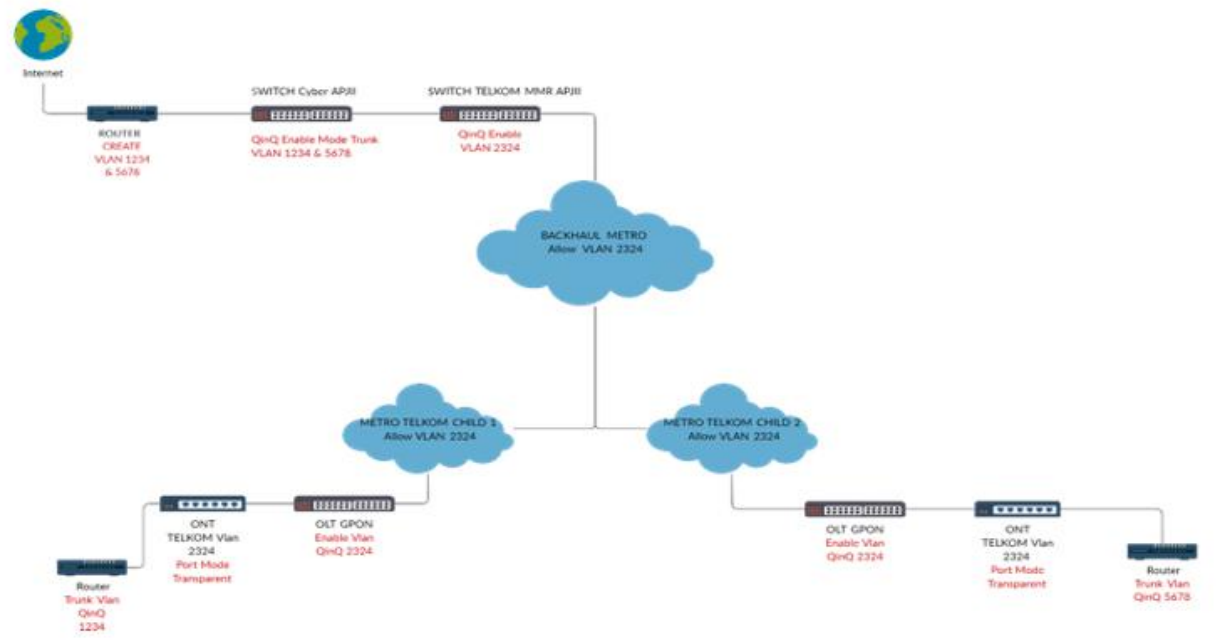

Gambar 4. 2 Topologi dengan QinQ

Gambar 4.2 menggambarkan topologi layanan yang sudah menggunakan metode VLAN QinQ. Pada topologi tersebut terjadi perubahan konfigurasi pada Switch di Backhaul sebagai perantara utama dengan pelanggan dan konfigurasi pada OLT dan ONT GPON yang sebelumnya belum menggunakan konfigurasi QinQ VLAN [12]. Pada Implementasi topologi di Gambar 4.2 peneliti dibantu oleh pelanggan untuk melakukan tag vlan QinQ atau CVLAN (Customer VLAN) dan 
pengetesan layanan yang dapat membuktikan encapsulation dari metode qinq ini berhasil.

C. Perancangan

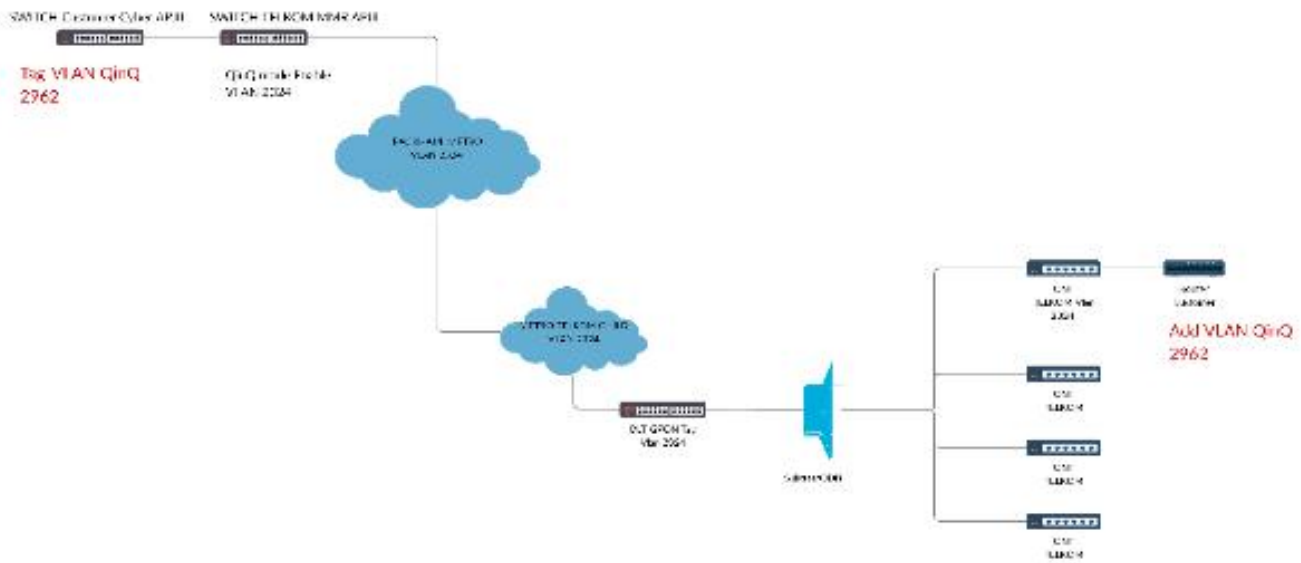

Gambar 4. 3 Rancangan Topologi dengan QinQ

Berdasarkan perancangan jaringan pada Gambar 4.3 peneliti menggunakan perangkat GPON OLT HUAWEI MA5600T untuk mengimplementasikan konfigurasi QinQ VLAN, namun untuk melakukan encapsulation pada perangkat pelanggan di MMR APJII peneliti menggunakan Switch FIBERHOME S5800 . Adapun perancangan konfigurasi mulai dari perangkat pelanggan sampai dengan End Point ( Router Client ) adalah sebagai berikut

Tabel 4.1 Konfigurasi pada Switch Pelanggan MMR APJII

\begin{tabular}{ccccc}
\hline No & Peruntukan & Port & Mode & VLAN \\
\hline 1 & $\begin{array}{c}\text { SW Pelanggan To } \\
\text { SW MMR APJII }\end{array}$ & xge-1/0/36 & Trunk & $\begin{array}{c}\text { VLAN ID QinQ yang } \\
\text { akan dilewatkan }\end{array}$ \\
2 & $\begin{array}{c}\text { SW Pelanggan to } \\
\text { Router Pelanggan }\end{array}$ & $\begin{array}{c}\text { Xge- } \\
\mathbf{1 / 0 / 3 8}\end{array}$ & Trunk & VLAN ID Client 2962
\end{tabular}

Tabel 4.2 Konfigurasi pada Switch MMR APJII 


\begin{tabular}{|c|c|c|c|c|}
\hline No & Peruntukan & Port & Mode & VLAN \\
\hline 1 & $\begin{array}{l}\text { SW MMR APJII } \\
\text { To SW Pelanggan }\end{array}$ & xge-1/2/1 & QinQ & 2324 \\
\hline 2 & $\begin{array}{c}\text { SW MMR APJII } \\
\text { To UPLINK } \\
\text { Metro }\end{array}$ & $\begin{array}{l}\text { Xge- } \\
1 / 1 / 1\end{array}$ & Trunk & 2324 \\
\hline \multicolumn{5}{|c|}{ Tabel 4.3 Konfigurasi pada OLT GPON } \\
\hline No & Peruntukan & Port & Mode & VLAN \\
\hline 1 & $\begin{array}{l}\text { GPON OLT To } \\
\text { UPLINK Metro }\end{array}$ & $\mathbf{0} / \mathbf{1 0} / \mathbf{1}$ & $\begin{array}{l}\text { Tag } \\
\text { Vlan }\end{array}$ & 2324 \\
\hline 2 & $\begin{array}{c}\text { GPON OLT To } \\
\text { ONT }\end{array}$ & $\begin{array}{c}\text { 0/1/12 ONT } \\
7\end{array}$ & QinQ & 2324 \\
\hline
\end{tabular}

Tabel 4.4 Konfigurasi pada ONT GPON

\begin{tabular}{ccccc}
\hline No & Peruntukan & Port & Mode & VLAN \\
\hline 1 & $\begin{array}{c}\text { GPON ONT To } \\
\text { OLT }\end{array}$ & $\begin{array}{c}\text { 0/1/12 ONT } \\
7\end{array}$ & QinQ & 2324 \\
2 & ONT To Client & LAN 1 - 4 & Transparent & 2324 \\
\hline
\end{tabular}

Tabel 4.5 Konfigurasi pada Router Pelanggan

\begin{tabular}{ccccc}
\hline No & Peruntukan & Port & Mode & VLAN \\
\hline 1 & Router Client To & Ethernet1 & Trunk & Vlan ID Client 2962 \\
& ONT & & &
\end{tabular}

\section{Implementasi}

Pada tahapan Implementasi penelitian menggunakan VLAN ID yang dilewatkan customer untuk menguji keberhasilan konfigurasi metode QinQ pada sistem jaringan informasi sampai dengan client [13]. Konfigurasi yang digunakan adalah sebagai berikut :

Konfigurasi pada Switch customer ke arah Switch MMR APJII SW.01.JKT.APJII-RZ.QFX$5100>$ show configuration interfaces xe-1/0/36 description TRUNK-TO-BACKHAUL-DWSQINQ-NEW;

mtu 9192;

unit 0 \{

family ethernet-switching \{

interface-mode

trunk; vlan \{

members [ 36 38-3942104 329 337-338 383414418456599785 822 903-904985997 


\section{$2362-$}

$23702372-237923942880291029162918-29202923 \quad 2925-2926 \quad 2928-2980 \quad 2982-2999$ 3006-

$30103012-3015$ 3017-3026 3028-3029 3031-3033 3036-3038 3040-3042 3050-3054 30563062

3064-3066 3068-d-3251 3256-32573695 3902 ];

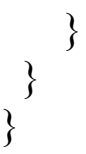

Pada perangkat customer menggunakan mode trunk untk menambahkan VLAN ID pada konfigurasi metode QinQ atau inner vlan double tagging. Nantinya VLAN ID Tersebut yang akan dilewatkan sampai dengan sisi client [14].

\section{Konfigurasi SW MMR APJII To SW}

Pelanggan SW02-APJII (config)\#interface xgigaethernet 1/2/1 SW02-APJII (configxge 1/2/1)\#port link-type access SW02-APJII (config-xge1/2/1)\#port default vlan 2324 SW02-APJII (config-xge1/2/1)\#dot1q-tunnel enable

\section{SW MMR APJII To UPLINK Metro}

SW02-APJII (config)\#interface xgigaethernet 1/1/1

SW02-APJII (config-xge1/1/1)\#port trunk allow pass vlan 2324

\section{Konfigurasi Pada GPON}

Setelah melakukan konfigurasi pada perangkat Switch, maka dilakukan konfigurasi pada GPON yang dimulai dari OLT sampai dengan ONT [15]. Konfigurasi pada GPON OLT dan ONT dilakukan dengan mengikuti Langkah sebagai berikut :

\section{Membuat VLAN ID pada OLT}

GPON01-MERAK(config)\#vlan 2324

GPON01-MERAK(config)\#vlan attrib 2324 q-in-q GPON01-MERAK(config)\#port vlan $23240 / 10 / 1$

\section{Membuat Line Profile-Id pada OLT}

GPON01-MERAK(config)\# ont-lineprofile gpon profile-id 777 profile-name "QINQ" GPON01-MERAK(config)\# mapping-mode port

GPON01-MERAK(config)\# tcont 1 dba-profile-id 20 GPON01-MERAK(config)\# gem add 1 eth tcont 1 GPON01-MERAK(config)\# gem mapping 10 et

\section{Membuat Service Profile-id pada OLT}

GPON01-MERAK(config)\# ont-lineprofile gpon profile-id 777 profile-name "QINQ" GPON01-MERAK(config)\# ont-port pots 2 eth 4

GPON01-MERAK(config)\# port vlan eth 1 transparent GPON01-MERAK(config)\# port vlan eth 2 transparent GPON01-MERAK(config)\# port vlan eth 3 transparent GPON01-MERAK(config)\#commit

4. Melihat ONT yang

GPON01-MERAK(config)\#display

belum

ont di autofind registrasi all

\begin{tabular}{|l|l|}
\hline Number & 7 \\
\hline
\end{tabular}




\begin{tabular}{|l|l|}
\hline F/S/P & $0 / 1 / 12$ \\
\hline Ont SN & 48575443 DDCA299A (HWTC-3E40139E) \\
\hline Password & $0 x 00000000000000000000$ \\
\hline Loid & \\
\hline Checkcode & \\
\hline VendorID & HWTC \\
\hline Ont Version & 150D.B \\
\hline Ont SoftwareVersion & V5R019C00S105 \\
\hline Ont EquipmentID & HG8245H5 \\
\hline Ont Customized Info & Telkom, Indonesia \\
\hline Ont autofind time & 2020-12-03 16:57:03+07:00 \\
\hline
\end{tabular}

Dapat dilihat slot yang terbaca pada F/S/P dan Number, adalah letak dari alokasi ONT pada OLT yang nantinya akan dibaca dengan $0 / 1 / 12$

\section{Konfigurasi Frame/Slot/Port untuk ONT}

GPON01-MERAK(config)\#interface gpon 0/1

GPON01-MERAK(config-if-gpon-0/1)\# ont add 127 sn-auth "48575443DDCA299A" omci ont-lineprofile-id 777 ont-srvprofile-id 777 desc "QINQ "

6. Membuat Service Profile-id pada OLT

GPON01-MERAK(config)\# ont-lineprofile gpon profile-id 777 profile-name "QINQ" GPON01-MERAK(config)\# ont-port pots 2 eth 4

GPON01-MERAK(config)\# port vlan eth 1 transparent GPON01-MERAK(config)\# port vlan eth 2 transparent GPON01-MERAK(config)\# port vlan eth 3 transparent GPON01-MERAK(config)\#commit

7. Registrasi Serial Number ONT

Melihat

$$
\text { ONT }
$$
yang belum

di registrasi

GPON01-MERAK("config)\#display ont autofind all

\begin{tabular}{|l|l|}
\hline Number & 7 \\
\hline F/S/P & $0 / 1 / 12$ \\
\hline Ont SN & 48575443 DDCA299A (HWTC-3E40139E) \\
\hline Password & $0 \times 00000000000000000000$ \\
\hline Loid & \\
\hline Checkcode & \\
\hline VendorID & HWTC \\
\hline
\end{tabular}




\begin{tabular}{|l|l|}
\hline Ont Version & 150D.B \\
\hline Ont SoftwareVersion & V5R019C00S105 \\
\hline Ont EquipmentID & HG8245H5 \\
\hline Ont Customized Info & Telkom, Indonesia \\
\hline Ont autofind time & $2020-12-03$ 16:57:03+07:00 \\
\hline
\end{tabular}

Dapat dilihat slot yang terbaca pada F/S/P dan Number, adalah letak dari alokasi ONT pada OLT yang nantinya akan dibaca dengan 0/1/12 7

8. Konfigurasi Frame/Slot/Port untuk ONT

GPON01-MERAK(config)\#interface gpon 0/1

GPON01-MERAK(config-if-gpon-0/1) \# ont add 127 sn-auth "48575443DDCA299A" omci ont-lineprofile-id 777 ont-srvprofile-id 777 desc "QINQ "

9. Membuat Service Profile-id pada OLT

GPON01-MERAK(config)\# ont-lineprofile gpon profile-id 777 profile-name "QINQ" GPON01-MERAK(config)\# ont-port pots 2 eth 4

GPON01-MERAK(config)\# port vlan eth 1 transparent GPON01-MERAK(config)\# port vlan eth 2 transparent GPON01-MERAK(config)\# port vlan eth 3 transparent GPON01-MERAK(config)\#commit

\section{Melihat ONT yang belum di registrasi}

GPON01-MERAK (config)\#display ont autofind all

\begin{tabular}{|l|l|}
\hline Number & 7 \\
\hline F/S/P & $0 / 1 / 12$ \\
\hline Ont SN & 48575443 DDCA299A (HWTC-3E40139E) \\
\hline Password & $0 x 00000000000000000000$ \\
\hline Loid & \\
\hline Checkcode & \\
\hline VendorID & HWTC \\
\hline Ont Version & 150 D.B \\
\hline Ont SoftwareVersion & V5R019C00S105 \\
\hline Ont EquipmentID & HG8245H5 \\
\hline Ont Customized Info & Telkom, Indonesia \\
\hline Ont autofind time & 2020-12-03 16:57:03+07:00 \\
\hline
\end{tabular}

Dapat dilihat slot yang terbaca pada F/S/P dan Number, adalah letak dari alokasi ONT pada OLT yang nantinya akan dibaca dengan 0/1/12 7 


\section{Konfigurasi Frame/Slot/Port untuk ONT}

GPON01-MERAK(config)\#interface gpon 0/1

GPON01-MERAK(config-if-gpon-0/1)\# ont add 127 sn-auth "48575443DDCA299A" omci ont-lineprofile-id 777 ont-srvprofile-id 777 desc "QINQ "

Konfigurasi Service Port pada ONT

GPON01-MERAK (config)\# Service-port vlan 2324 gpon 0/1/12 ont 7 gemport 1 multi- service user-vlan other-all tag-transform default

\section{Konfigurasi pada perangkat router Client}

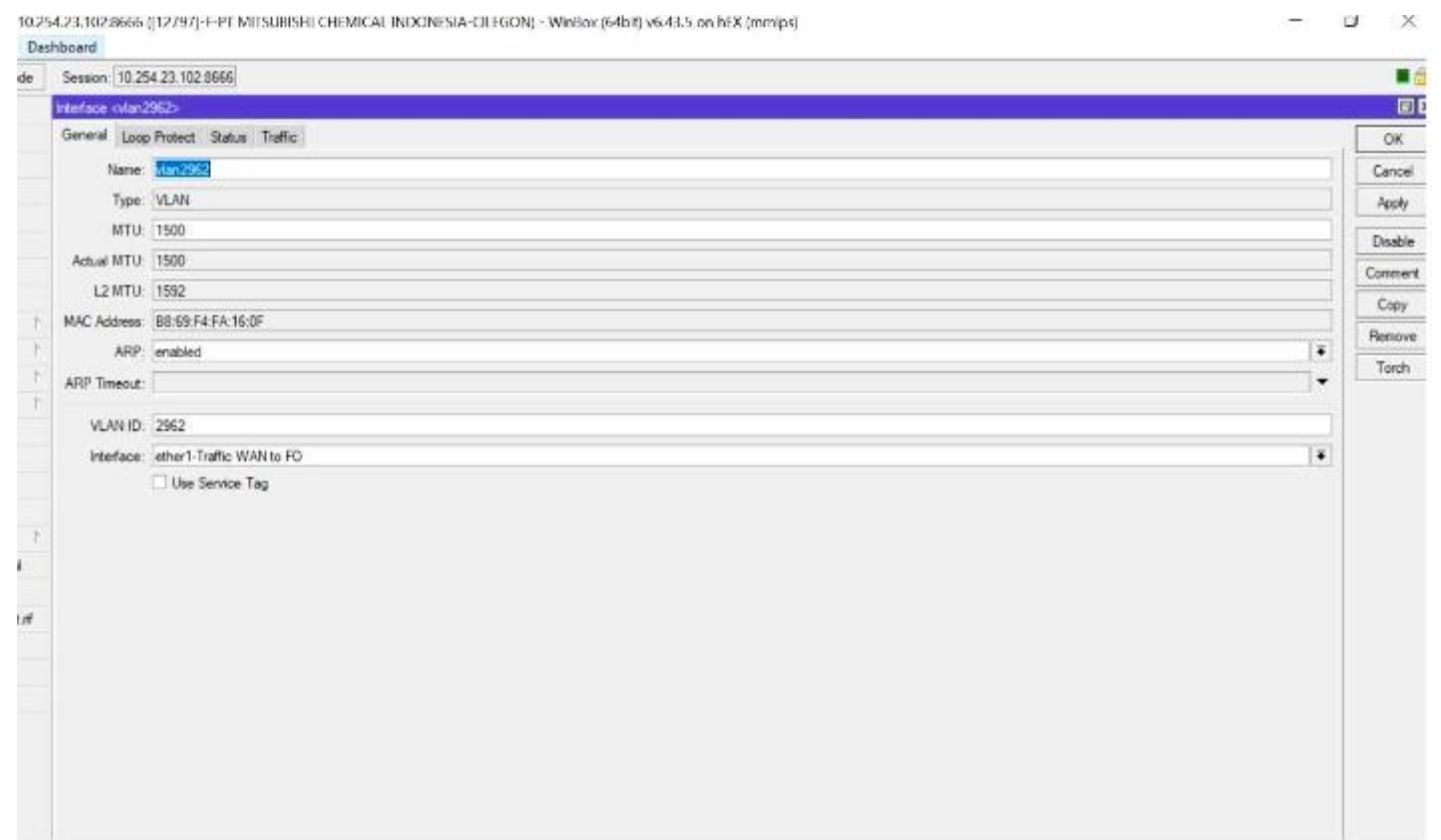

Gambar 4. 4 Tampilan Konfigurasi di sisi Client 
Konfigurasi di sisi client dilakukan oleh pelanggan dengan cara menambahkan VLAN ID pada interface ke arah router yang terkoneksi langsung dengan ONT.

\section{E. Pengetesan Layanan}

Pengetesan layanan dengan cara cek Mac-Address dari client dan Test PING dengan IP yang dipasang pada CVLAN untuk memastikan layanan sudah berjalan dengan konfigurasi VLAN QinQ.

\section{Cek Mac-Address :}

Memastikan VLAN ID yang sudah di tag dari client terbaca pada ONT dan sudah terbaca pada OLT GPON.

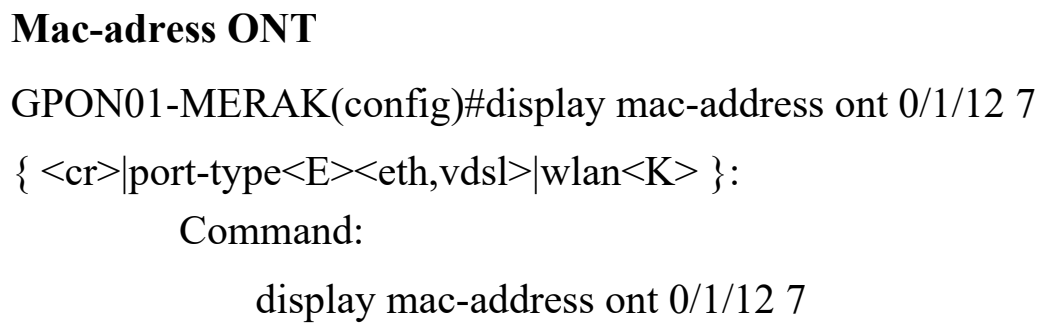

Total: 2

\section{Mac-Address OLT}

GPON01-MERAK(config)\#display mac-address vlan 2324 It will take some time, please wait... 


\section{SRV-P BUNDLE TYPE MAC MAC TYPE F /S /P VPI VCI VLAN ID}

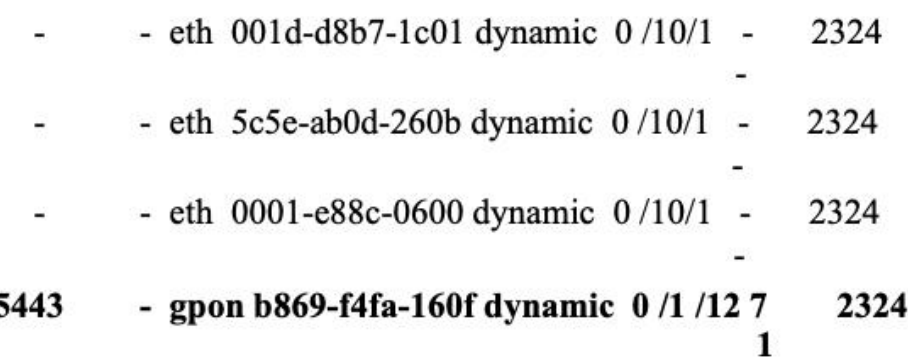

\section{Test Ping :}

Test ping dengan cara menggunakan interface VLAN pada VLAN ID yang akan dilewatkan dari Client sampai dengan Backhaul . Pada sisi Client menggunakan IP 10.254.23.102/30 dan pada sisi Backhaul menggunakan 10.254.23.101/30 sebagai Gateway untuk VLAN ID 2962.

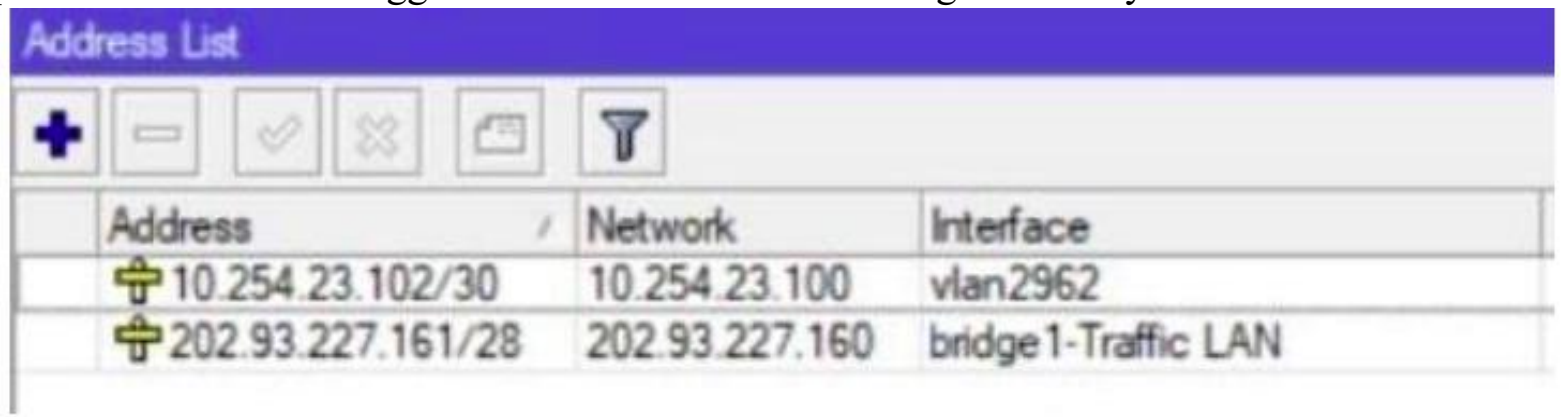

Gambar 4. 5 Konfigurasi IP interface VLAN

Ping Test dilakukan dengan dari sisi Client ke sisi Backhaul dengan cara mengirimkan paket ke arah Gateway yang memiliki IP 10.254.23.101/30.

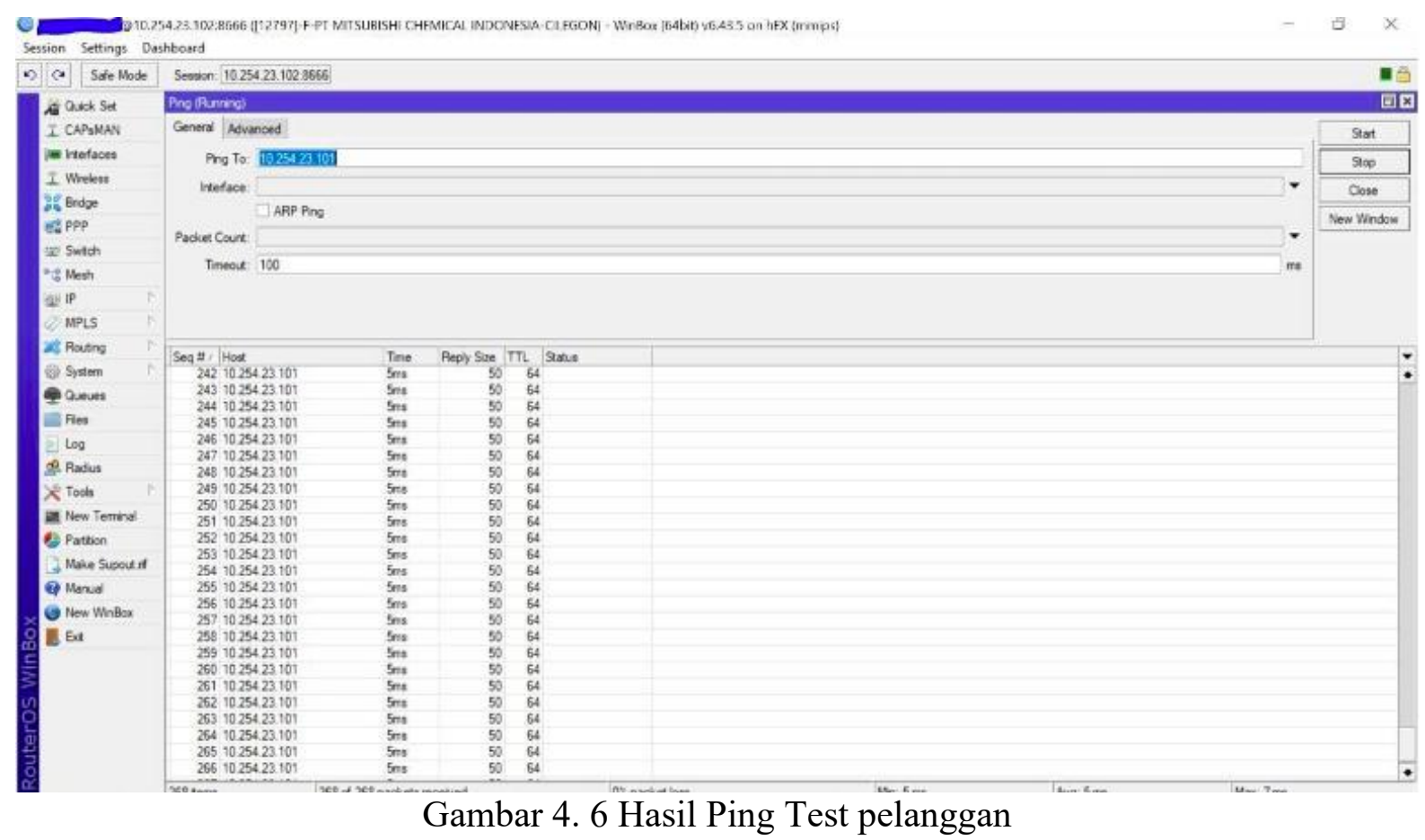

\section{F. Monitoring Layanan}


Monitoring layanan dilakukan dengan cara melakukan test ping dalam kurun waktu tertentu dan melakukan pengecekan kapasitas yang tersedia pada layanan dari Backhaul sampai dengan sisi Client.

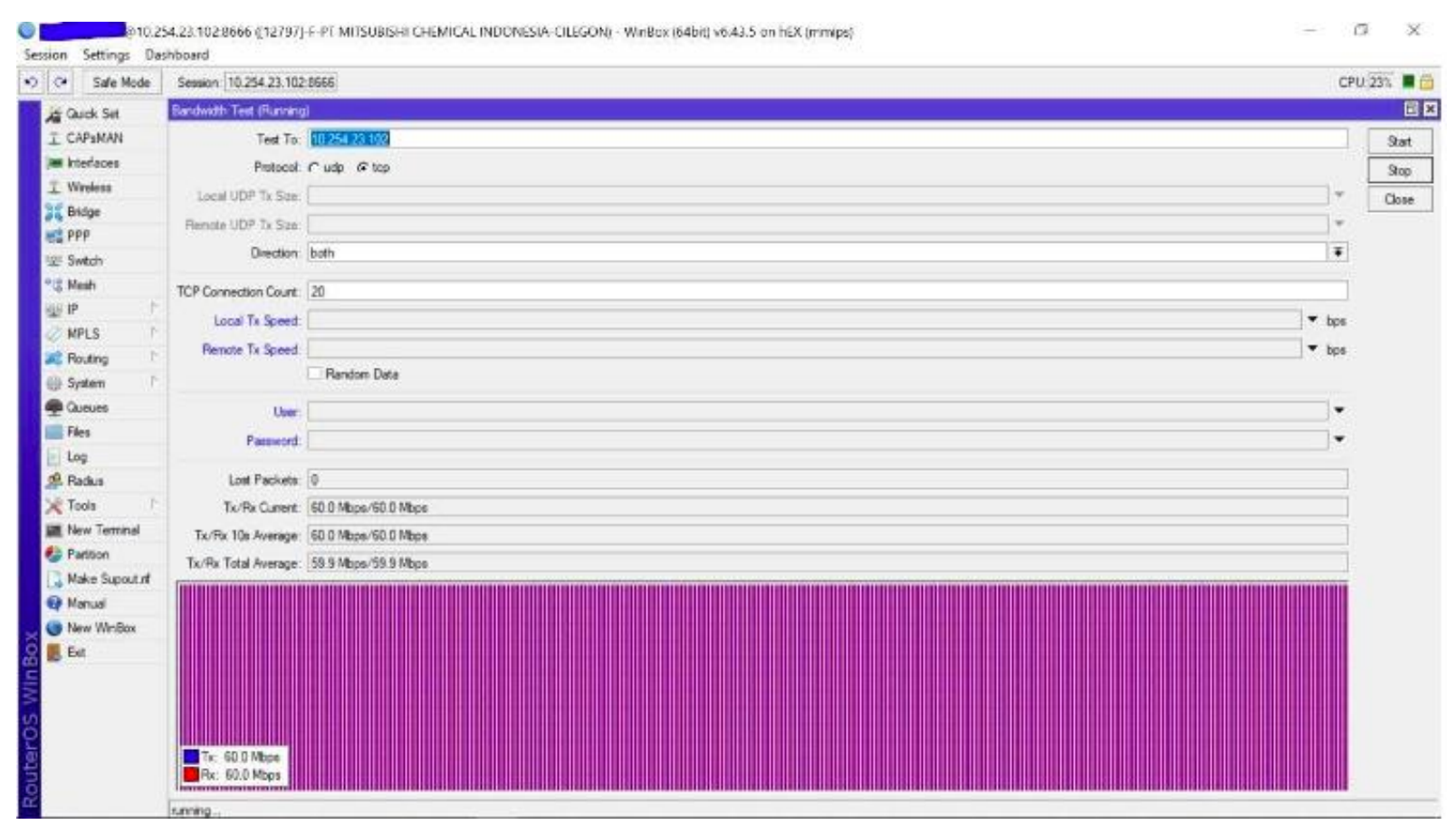

Gambar 4. 7 Monitoring Layanan Pelanggan

\section{KESIMPULAN}

Kesimpulan yang diperoleh dari penelitian ini adalah sebagai berikut :

1. Metode QinQ VLAN dapat diimplementasikan pada teknologi GPON (Gigabit Passive Optical Network) dengan menggunakan konfigurasi port Transparent pada ONT guna melewatkan VLAN ID apapun yang di tag ke arah ONT kemudian diterjemahkan ke dalam 1 VLAN ID yang berguna sebagai penghubung antara Backhaul dan Child.

2. Pada satu ONT yang sudah di konfigurasi dengan metode QinQ tidak dapat melakukan konfigurasi lain baik port mode acces atau pun mode trunk karena pada ONT tersebut sudah menggunakan Lineprofile-id dan Service Profile-id yang di khususkan untuk metode QinQ.

3. Jumlah Frame yang dapat dilewatkan tergantung pada spesifikasi dari ONT yang digunakan

\section{SARAN}

1. Memaksimalkan jumlah Frame yang dapat dilewatkan dengan menggunakan spesifikasi yang mendukung pada jaringan GPON. 
2. Pada VLAN QinQ yang sudah berhasil dilewatkan, dapat menggunakan tambahan konfigurasi routing untuk dapat memaksimalkan penggunaan VLAN QinQ.

\section{REFERENSI}

[1] T. Arfiansyah, "PLANNING DESIGN NETWORK ICT WITH GPON TECHNOLOGY (STUDI KASUS: OFFICE INDOMOBIL TOWER JAKARTA)".

[2] M. S. Bahry and B. Sugiantoro, "Analysys and Implementation IEEE 802.1 Q to Improve Network Security," IJID (International Journal on Informatics for Development), vol. 6, no. 2, pp. 28-33, 2017.

[3] M. A. Ghani, "ANALISIS PERFORMANSI QUALITY OF SERVICE (QOS) PADA JARINGAN MULTI PROTOCOL LABEL SWITCHING DENGAN METODE INTSERV," Jurnal Manajemen Informatika, vol. 9, no. 2, 2019.

[4] B. Basri and A. Qashlim, "Relay Kontrol Menggunakan Google Firebase dan Node MCU pada Sistem Smart Home,” Technomedia Journal, vol. 6, no. 01 Agustus, 2021.

[5] I. Aramico, "Activation and Monitoring of Customer Internet Networks Using GPON Technology on PT. Moratelematika Indonesia," 2019.

[6] R. A. A. Rahman and A. Adhitya, "Perancangan Sistem Informasi Pengusulan Kenaikan Pangkat Berbasis Web Pada Korps Marinir TNI AL," Technomedia Journal, vol. 6, no. 01 Agustus, 2021.

[7] H. Sulistiani, A. Yuliani, and F. Hamidy, "Perancangan Sistem Informasi Akuntansi Upah Lembur Karyawan Menggunakan Extreme Programming," Technomedia Journal, vol. 6, no. 01 Agustus, 2021.

[8] E. Prasetyo, A. Hamzah, and E. Sutanta, "Analisa Quality Of Service (Qos) Kinerja Point To Point Protocol Over Ethernet (Pppoe) Dan Point To Point Tunneling Protocol (Pptp)," Jurnal JARKOM Vol, vol. 4, no. 1, 2016.

[9] H. Septianto and R. Sirait, "PERENCANAAN KONFIGURASI INTERFACE METRO ETHERNET DOT1Q MENJADI QINQ DI PLAZA INDONESIA,” Arsitron, vol. 9, no. 01, pp. 43-49, 2019.

[10] V. P. Heryanto, T. A. Riza, and G. Gaatot, "Simulasi Dan Analisa Qos Multiprotocol Label Switching Untuk Layanan Metronet Pada Jaringan Pt Indonesia Comnets Plus (icon+)," eProceedings of Applied Science, vol. 5, no. 3, 2019.

[11] K. Nalakhudin, M. Imron, and M. A. W. Prasetyo, "Pemanfaatan Notifikasi Telegram Untuk Monitoring Perangkat CCTV Rumah Sakit Orthopaedi Purwokerto," Technomedia Journal, vol. 6, no. 01 Agustus, 2021.

[12] R. Rosyid and M. A. W. Prasetyo, "Robot Peraga 12 Gerakan Pengaturan Lalu Lintas Berbasis Arduino Mega 2560," Technomedia Journal, vol. 5, no. 2, pp. 193-205, 2021.

[13] B. D. Wicaksono and S. Anggraeni, "Perancangan Website Sistem Informasi Transaksi Tagihan Layanan Purna Jual Properti Pada Pollux Properti Indonesia," TMJ (Technomedia Journal) Vol. 5 No. 2 Februari 2021, p. 132, 2021.

[14] I. Muhamad, W. Hidayat, and I. Handayani, "Perancangan Sistem Informasi Persediaan Barang Pada PT. Pacific Paint Menggunakan PHP dan MySQL," Technomedia Journal, vol. 5, no. 2, pp. 182-192, 2021.

[15] A. S. Rafika, E. Febriyanto, and E. Safriyati, "Perancangan Modul Trainer Interface Mikrokontroler Berbasis ESP32 Sebagai Media Pembelajaran Pada Mata Kuliah Embedded System," Technomedia Journal, vol. 5, no. 1 Agustus, pp. 118-131, 2020. 